International Journal of Engineering \& Technology, $7(4.34)(2018) 153-158$
SPC
Website: $w w w . s c i e n c e p u b c o . c o m / i n d e x . p h p / I J E T$
Research paper

\title{
Organizational Justice from the Perspective of Potential Applicants
}

\author{
Hasnun Anip Bustaman', Abdul Malek A. Tambi²* \\ ${ }^{1}$ Faculty of Business Management, MARA University of Technology, Bukit Ilmu 18500 Machang, Kelantan, Malaysia \\ ${ }^{2}$ Faculty of Applied Social Sciences, Universiti Sultan Zainal Abidin, Gong Badak Campus, 21300 Kuala Nerus, Terengganu, \\ Malaysia \\ *Corresponding author E-mail: malekahmad@unisza.edu.my
}

\begin{abstract}
This paper reviews the recent advancement of organizational justice influencing the people from outside organizations, which has been gaining keen attention from scholars lately. Precisely, this paper aims to construe organizational justice with a greater emphasis on the potential applicant attraction. The discussion involved the elementary of four justices encompassing procedural justice, distributive justice, interpersonal justice and informational justice in the eye of potential applicant. Finally, this paper enlarged the conceptuality of study by providing some arguments of appropriate methodology for empirical testing.
\end{abstract}

Keywords: Recruitment and Selection; Organizational Justice; Signaling Theory; Applicant Attraction.

\section{Introduction}

The organizational asset of human resource is paramount important for organization earning competitive advantages [1-4]. Because of that, organizations racing to hire the best talent from a labor market. To be the champion, organization must perceive as attractive [5] and two recent meta-analytical reviews reveals that the predictor of work environment of the organizational characteristic given the most attractive variable to potential applicant $[6,7]$. There are varieties work environments of organizational characteristic in which attractiveness is associated, the focus of a study plays an important role. In regard to present study, the organizational justice of the work environment is the central, mainly because scholars have only recently begun to investigate third party individuals perception of organizational justice [8].

\section{The Third-Party Organizational Justice Study}

Over the past years, studies on organizational justice have mostly concentrated on employees inside an organization. Among others are studies on victims of unfair treatment, employees of injustice organization as well as colleagues of victim. Some other scholars in addition, have their take on study on transgressor [9-12]. Much of all of these studies on organizational justice were mainly focusing on the aforementioned aspect. However, little research has been done on how organizational justice affects the third-party individual's perception/outsider; an aspect of organizational justice which deems important in order to have a better understanding of the relationship between potential applicants and organizational justice as a whole. Not until recently do scholars and researchers have started to investigate the perception of third party individual's/outsider on organizational justice; a body of research which will be put into discussion in this particular paper [8].
The third-party observer is defined as a person who is not directly impacted by the unfairness in organization but who nonetheless may make fairness judgments of the event. The third parties being outlined by the scholars are company's customers, its potential applicants and members of the public. Although they are the outsiders of organization but their perspectives on organizational justice treatment is important to group and organization level [13]. Table 1 shown studies that prove the concept is significant important to third party categories. Organizational justice is a universal concept seems like important characteristics even to the outsiders in recent studies. Such as an important characteristic to outsiders, the concept anticipated to influence potential applicants also outsider of organization in selecting a place of work.

To investigate the impacts of organizational justice to the outsiders of the organization, it is fairly important to note how does this practice of organizational justice making their way out to the general public. One of the reasons is the emergence of communication technology such as Facebook, Twitter, and Instagram among others. The social media operates as a platform for electronic discussion where individuals post information, raise questions, and share experiences $[14,15]$. It is common these days that employees regularly lampoon employers on Youtube [16] and compare benefit packages on blogs [17]. Other than that, members of organizational identity groups (e.g., employees, former employees, clients, and employees of competitors) regularly share information on sites designed to encourage discussions of customer gripes [18], company ethics [19], and the quality of work life [14]. The information that was initially intended for friends and family has later reached a wider audience as outsiders use social networking sites for background checks [20].

By using these internet resources, individuals with varying degrees of organizational affiliation are brought together in a passionate debate on the effective and ineffective ways of which organizations operate [21]. Inadvertently, social media has changed the status quo in keeping the privacy of organization which makes it increasingly difficult to keep secrets on either side of the organi- 
zational fence. For this very reason of ease of accessing even the practice or malpractice of an organization, scholars and practitioners alike have contended organizational justice as having a greater impact beyond the insides of organization and out to the potential applicants in this era of emerging communication technology.

Table 1: Organizational Justice Study toward Third Party Categories

\begin{tabular}{|c|c|l|c|}
\hline No. & References & \multicolumn{1}{|c|}{ Topics } & $\begin{array}{c}\text { Third Party } \\
\text { Categories }\end{array}$ \\
\hline 1. & {$[22]$} & $\begin{array}{l}\text { A justice framework for under- } \\
\text { standing how guests react to hotel } \\
\text { employee (mis) treatment }\end{array}$ & Customer \\
\hline 2. & {$[23]$} & $\begin{array}{l}\text { Witnessing incivility among } \\
\text { employees: Effects on consumer } \\
\text { anger and negative inferences } \\
\text { about companies }\end{array}$ & Customer \\
\hline 3. & {$[24]$} & $\begin{array}{l}\text { Fairness lies in the heart of the } \\
\text { beholder: How the social emo- } \\
\text { tions of third parties influence } \\
\text { reactions to injustice. }\end{array}$ & $\begin{array}{c}\text { Member of } \\
\text { general pub- } \\
\text { lic }\end{array}$ \\
\hline 4. & {$[21]$} & $\begin{array}{l}\text { The electronic water cooler: In- } \\
\text { siders and outsiders talk about } \\
\text { organizational justice on the } \\
\text { internet. }\end{array}$ & $\begin{array}{c}\text { Member of } \\
\text { general pub- } \\
\text { lic }\end{array}$ \\
\hline 5. & {$[22]$} & $\begin{array}{l}\text { Employees' reactions to peers' } \\
\text { unfair treatment by super- visors: } \\
\text { The role of ethical leadership. }\end{array}$ & \begin{tabular}{c} 
Coworker \\
\hline
\end{tabular} \\
\hline
\end{tabular}

One of the recent studies upholding this concept was the study on the ways hotel management treats its staff [22] and the ways the employees treat one another in an uncivillized manner [23], significantly predict guests' respond to the organization. Through social media, [21] biases that happened within the organization [24] and bad gossips [25] that spread beyond the company's fence to customers, have a significant effect to outsiders. In short, the value of justice is apparent as an important characteristic even to the outsiders and the portrayal of this value should influence potential applicants' attraction in selecting a place of work. Nevertheless, there were relatively scarce studies over the last few years in particular from 2005 to 2015 which had directly highlighted the relationship between organizational justice and applicant attraction; one of the outlined third party [13]. Hence, the researcher asserts that it is critical to execute a study to further understand this potential applicant attraction perception on organizational justice.

\section{Organizational Justice Determinants}

Present study defines the dimension of organizational justice as per general understanding. Organizational justice dimensions much in the early research explored employees' perceptions of the distributive and procedural fairness of specific organizational policies and decisions [9]. Research integrating procedural and distributive justice has found consistent support for a two-factor conceptualization of organizational justice [26]. Beginning in the late 1980s, organizational justice researchers expanded beyond the traditional procedural and distributive types of justice, and began to explore the interactional side of organizational justice [27]. Recent research suggests that justice perceptions are most aptly conceptualized along with four dimensions - distributive, procedural, interpersonal, and informational, e.g. [28-31]. The contemporary model has been received more than 4000 citations since it was released in year 2001 [29].

Colquitt tested the model to undergraduates and employees. This study specifically refers to outcome from undergraduate data is likely similar with present study concept. The outcome of the study reveals the model best fitting is four-factor model which are distributive, procedural, interpersonal, and informational justice. The worst fitting model is the one-factor model. Assessing whether the fit of a model is significantly better than other models is traditionally done using a chi-square difference test. For example, the difference in chi- square between the three and four-factor models is 195.90, which is itself distributed as chi-square with $(413-406=7)$ degrees of freedom. The fact that this value is statistically significant would suggest that the four-factor model is significantly better than the three-factor one. However, the chisquare difference test is only appropriate in comparing "nested" models. One model is nested within another if the model is a special case of the other (e.g., a more restricted version of it). There is some debate about whether a four-factor model is a more restricted version of a three-factor model because a new latent variable has been introduced. Thus, model comparisons can be made using the $90 \%$ confidence interval of the RMSEA. This comparison shows that the four-factor model is significantly better than the three-factor model because their confidence intervals do not overlap (RMSEA: 0.055, CFI: 0.92, IFI: 0.92). Thus, present study employs four dimensions of organizational justice to investigate the constructs relationship with applicant attraction.

\section{Third Party Organizational Justice in the Eye Potential Applicant}

Investigating the rationale of reviewing the impacts of organizational justice on potential applicant attraction, it is worth noted that while more publications of empirical studies had flourished which suggested that organizational justice has significant impact on job choice, there are very little findings about the impacts of organizational justice on potential applicant attraction; also one of the aspects of recruitment outcome study [32-34]. The others being applicants' intention to apply and the previously mentioned job choice [6]. One reason which leads to the lack of research on said field is due to the Proposition 19 of the Application Reaction Model by [12] that mentioned "Procedural justice and the fairness of the selection process will be more strongly related to both individual outcomes, such as acceptance decisions and application recommendations". This had led to a flock of studies being done on organizational justice and job choice. Hence, this explains the urgent needs to investigate the effect of organizational justice directly to the potential applicant attraction even further.

Apart from that, the studies on job choice have appeared to be incapable of achieving a thorough understanding on the effect of organizational justice on potential applicant attraction. This is largely since study on job choice is basically a study on the behaviour of potential employee who had been chosen from the job application towards the organization, e.g. [32-34]. Potential applicant study on the other hand, investigates the attraction perception or the attitude of potential applicant towards organizational characteristics $[35,36]$. That being the reason, it is imprecise to refer to behavioural study to understand the attitude of potential applicant towards organizational characteristics. A designated study instead must be established to precisely investigate the relationship between organizational justice and applicant attraction. Moreover, job choice study is seen to be having of less importance compared to studies on applicant attraction perception [6]. It is suggested that studies on organizational justice should henceforth emphasize on the more important aspect of recruitment outcome which is on potential applicant attraction given the utmost significant impact of organizational justice concept to the third-party; thus, providing more insights to organization in recruiting employee.

Reviews of related literature have revealed that the study of concept related to organizational justice was last published two decades ago. In a study by [37], a total of 297 respondents applying for a $\mathrm{Ph}$. D program at a university were being tested based on Gilliland's Applicant Reaction Model. The task involved respondents answering mail questionnaires. Finding had it that one of the dimensions of organizational justice namely the fair process had a significant relationship to applicant attraction. However, the study also tested the other aspects of recruitment outcomes including job choice and recommendation intention simultaneously. Verily, this had made the reliability of the study questionable as principles of recruitment study demand for separate study to investigate each of the outcomes [7]. Besides that, in the last 20 years, there are two new additions to the previously known two dimensions of organi- 
zational justice. Knowledge advancement had contributed to the quite recently developed concept; the four dimensions of organizational justice [29]. All in all, this present study is an initiative of an all-in study to understand the organizational justice with the new dimensions related to applicant attraction.

It has been found that potential applicants mostly have incomplete information of organizational justice. To overcome this lack of information, scholars have suggested to interpret information being received as signals about the organizations' working conditions [38]. The signaling theory-based proposition suggests that organizational characteristics provide applicants with information about what and how it would be like to be a member of an organization. This is because such characteristics can be interpreted as providing information about working conditions in that organization [39]. To illustrate, organizational characteristics such as corporate social performance [39], organization's romance policy [40], flextime and flexplace [41] provide signals about the firm's working conditions. Similarly, organizational characteristic which displays organizational justice provides signals about working conditions in the organization and the characteristic denoting certain organizational moral, value and norms [13]. As [42] noted, people are more attracted to organizations they view as having values and norms they deem important. As an organization's justice is thought to signal certain values and norms, it seems likely that this characteristic will influence applicants' perceptions of the place of work (attraction). Therefore, the present study which is built from signaling theory anticipates that organizational justice may help organizations to receive positive feedbacks from potential applicants.

Thus, the proposition developed:

P1: Perceived organizational justice is positively related to applicant attraction.

\section{Organizational Justice Determinants in the Eye of Potential Applicant}

As previously mentioned, earlier researches on organizational justice dimensions mainly explored two dimensions that is employees' perceptions of the distributive as well as procedural fairness of specific organizational policies and decisions [9]. These researches which integrate procedural and distributive justice have found consistent support for a two-factor conceptualization of organizational justice [26]. However, in the late 1980s, organizational justice researchers began to explore new concepts and dimensions that were beyond the traditional procedural and distributive types of justice, and the studies started to expand to the interactional side of organizational justice [27]. A recent research had also suggested that justice perceptions are most aptly conceptualized along with the four dimensions - distributive, procedural, interpersonal, and informational [28, 29, 30, 31]. The contemporary model has ever since received more than 4000 citations upon released in 2001 [29].

\subsection{Linking between Procedural Justice and Applicant Attraction}

In [31] defined procedural justice as establishing certain principles specifying and governing the roles of participants in the decisionmaking processes or influence over the outcomes. In [43] explained in their well-known book, Blue Ocean Strategy that specifying and governing the roles of participants in decision-making processes will lead to intellectual and emotional recognition. Emotional recognition is a positive feeling towards organization attraction [44]. In short, perception on procedural justice leads to emotional recognition for which applicant feel attracted to an organization. Previous study by [37]. For example, revealed procedural justice as significant to applicant attraction. This finding was further supported by [40] in a study which investigated the same concept and the results which came out from its heterogene- ous respondents supported the results of the previous study. Thus, proposition between procedural justice and applicant attraction developed:

P1a: Perceived procedural justice is positively related to applicant attraction.

\subsection{Linking between Distributive Justice and Applicant Attraction}

In [45] defined distributive justice as "the fairness of the way outcomes is distributed". People in general are inclined to protect their self-interest or restore their self-interest [13]; thus, an organization with a fair distributive system is perceived as a positive place to work as it is seen as would be able to protect employees' self-interest. This positive perception consequently may increase potential applicants' attraction towards the working place. In other words, the perceptions on an organization's distributive justice would positively contribute to applicant attraction. This concept however, has never been investigated directly as available studies such as the one by [34] mainly focused on the later stages of recruitment outcomes. This study showed that there was a positive relationship between perceived distributive justice to intention to accept job offer. The finding aligned with the study carried out by [46]. With this thought in mind; that distributive justice has a positive impact on intention to accept job offer; the researcher develops a proposition that distributive justice should also have a similar positive relationship with applicant attraction and that studies on the relationship of the latter two variables are anticipated to produce similar outcome.

P1b: Perceived distributive justice is positively related to applicant attraction.

\subsection{Linking between Interpersonal Justice and Appli- cant Attraction}

The concept of interpersonal justice relates to how individuals are treated during the implementation of procedures (respect, concern for one's troubles, and treatment with dignity) [47]. Morally, potential applicants will positively respond to the good/appropriate/well-mannered treatment of others because it is the "right thing to do" [13]. To illustrate, a situation in an organization where the underperformers are still being treated respectfully and professionally by his/her supervisor during performance appraisal meeting, is perceived as a positive place to work. Potential employees perceive the scenario positively and this in turn persuades them to apply for job in the organization [48]. This view was further supported through a study by [40] which demonstrated that there has been a positive and significant relationship between interpersonal justice and applicant attraction. In [33] who studied the relationship between interpersonal justice and job choice also found a consistent significant relationship between the two variables. The positive impact of interpersonal justice on different aspects of recruitment outcomes was further strengthened in a study by [46] who found that interpersonal justice as well has significant relationship to job choice and consistently highlighted positive relationship between interpersonal justice and intention to accept job.

Based on these apparent findings relating interpersonal justice positively to the later stages of recruitment outcomes, it is anticipated that this present study would also achieve the same outcome in proving that interpersonal justice does affect applicant attraction positively.

P1c: Perceived interpersonal justice is positively related to applicant attraction. 


\subsection{Linking between Informational Justice and Appli- cant Attraction}

In [49] defined informational justice as the explanations provided by decision makers to clarify why procedures are implemented in a certain way or why outcomes are distributed in a certain fashion. In [31] referred to informational justice as whether one is being truthful and provides adequate justifications when things go badly. A study by [46] revealed that informational justice did have a significant positive relationship to intention to accept job; an aspect of the later stage of recruitment outcome. For this reason, it is fair to expect that informational justice would have the similar significant positive relationship with applicant attraction with the latter being the most important aspect of recruitment outcome.

On another note, study on informational justice is significant to be taken to extra mile in view of the development of technology [13]. This explains why this present study is relevant to determine the impact of informational justice on applicant attraction. Thus, proposition developed:

P1d: Perceived informational justice is positively related to applicant attraction.

\section{The Conceptual Model}

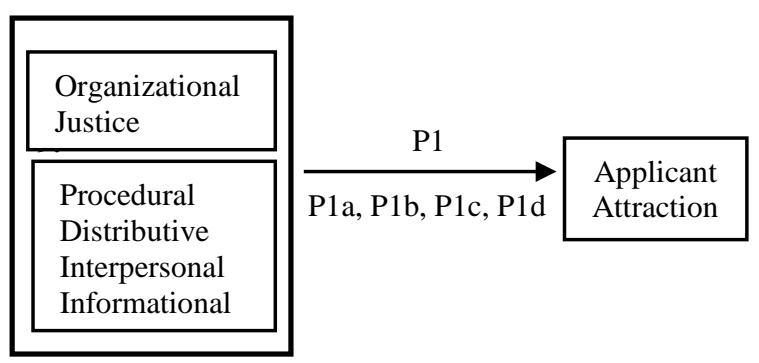

Fig. 1: Model of Organizational Justice to Applicant Attraction (MOJA)

Fig. 1 portrays the relationship between organizational justice and potential applicant attraction derived from theory, concepts and logics as highlighted in the earlier discussion. The model might be used as a guideline to understand further the organizational justice and applicant attraction concept.

\section{Proposed Research Design}

There have been several calls regarding the need to implement research designs that improve our knowledge about causal relationships [50-55].

One of the reasons for this urgent need is because the commonly used cross sectional study which consists of passive observation designs; provided vague answers to the causal relationship [56, 57]. In addition, the findings of cross sectional study which were gained by simply asking people about their preferences on fairness were deemed insufficient [58]. In light of experimental control design (quasi-experimental), this method permits strong causal inferences and enables researchers to better assess the independent effects of variables [39] which would eventually help to enhance the understanding of the causal relationships between variables [59]. Hence, this present study is seen to be in line with the scholars' call by suggesting the use of quasi-experimental design which fares better to understand causal relationships [60].

Quasi-experimental design has the properties of both experimental and non-experimental studies on one part and the other. A quasiexperimental study can be carried out in a controlled environment, which involves the researcher (or someone else) introduces the intervention or stimulus to study its effects. The study population is being placed in a controlled situation such as in a room [61]. Quasi-experimental consists of presenting participants with carefully constructed and realistic scenarios to assess dependent varia- bles including intentions, attitudes, and behaviors to determine which pieces of information are most influential in determining decisions [60]. The term Quasi-experimental design deliberately varies across disciplines [62]. In marketing it is called conjoint analysis stated preference models or trade-off analysis $[63,64]$. Researchers on problem-solving with computer and information systems on the other hand, use the term protocol analysis [65]. In environmental and social policy research, the terms contingent preference, contingent choice or analytical hierarchical process models are often used $[66,67]$. Finally, in strategy and organizational behavior/human resource, researchers generally use the term policy-capturing study $[68,69]$.

Policy capturing is a research design that has increasingly been used and discussed in the past few decades, with 600 papers citing the technique in their titles alone [70]. By using regression-based methodology to capture the cognitive processes underlying judgments, the results of policy capturing demonstrate the most important aspects considered by decision makers in making decisions. Hence, many researchers including organizational studies scholars have used this technique to carry out decision-making or judgment task research in effort to study a variety of decisionmaking processes about organizational issues [62]. Several studies that had been cited as adopting this technique are marketing researches which purpose was to seek for understanding of consumers' purchasing decisions, strategic researches that were to investigate the factors that affect executives' decisions about strategic initiatives for their firms and also organization behavior/human resource researches which seek to study personal and organizational characteristics that influence personnel selection, job choice, turnover and other aspects of the employment relationship. Statistically, the processes of decision-making on job choice, ratings of job applicants and performance evaluation made up approximately one half of the types of decisions making processes being studied [71].

As previously highlighted, the conceptual understanding underlying this present study is signaling theory; a theory that underlines respondent's perception to decide based on depicted scenarios. The concept is basically in line with policy capturing study which makes use of real-life scenarios to investigate respondents' decision-making process [44]. Unlike cross-sectional design that requires more of respondent's self-insight which seems to be providing minimum impact for the study underlying the theory, policy capturing concept on another note, acquires findings on respondent's decision-making based on their overall judgments on multiattribute scenarios. Asking individuals to make overall judgments about multi-attribute scenarios is more similar to actual decisionmaking process to solve problems, and hence more realistic, than is a self-report attribute design [72]. This has therefore, justify the study design underlying the theory. Several studies in fact have been found to be deploying the methodology in understanding applicant attraction concept such as the likes of studies on corporate social responsibility [39,42], corporate citizenship [73], organizational reputation $[74,75]$, organizational culture $[76,77]$ and a few others. This has strengthened the fact that policy capturing design is indeed appropriate for the study underlying signaling theory and in tandem with present study suggestion.

Last but not least, policy capturing weakens the social desirability effects, which are often found in self-report attribute method, by indirectly assessing the importance of cues [71]. The methodology comes from the ability of the researcher to experimentally manipulate cue values. By minimizing variable intercorrelations, researchers have been able to avoid the problems of multicollinearity often found with field data and enhance the capacity to assess the independent effects of cues [78]. Furthermore, policycapturing is typically carried out at individual level. This means that a separate model is generated for each decision maker, although aggregate analyses of groups of individuals can also be conducted. These separately made individual analyses would allow for a more in-depth assessment of differences between individuals [71]. In conclusion, it is hopeful that the arguments would shed some lights that policy capturing study has very much in 
support of applicant attraction study with several benefits otherwise would never be obtained from other methodologies.

\section{Conclusion}

Conceptually, the organizational justice seems like important construct to the potential applicant attraction although they are from outside organization. The other outsider parties except potential applicant, the empirical study on those people has been extensively made public lately. In other words, the available research papers found not many researchers interested to study on the organizational justice associated with the potential applicant attraction. Most probably difficulty to understand the concept behind the subject. Thus, this paper initiated by introducing the conceptuality of the organizational justice in the eye of potential applicant optimistically will contribute to the new understanding and furthermore will flourish the empirical study on the concept. To motivate more, this study provided the arguments on the methodology named policy capturing study that suitable methodology to empirically understand the concept.

\section{Acknowledgement}

The authors would like to thank the Research Management, Innovation and Commercialization Centre, Universiti Sultan Zainal Abidin, Terengganu, Malaysia for providing the financial assistance to support the publication fee of this article.

\section{References}

[1] T. H. Cox and S. Blake, "Managing cultural diversity: Implications for organizational competitiveness," Academy of Management Perspectives, 5(3), 45-56, 1991

[2] M. Kaliprasad, "The human factor 1: Attracting, retaining, and motivating capable people," Cost Eng., 48(6), 20-26, 2006.

[3] A. A. Lado and M. C. Wilson, "Human resource systems and sustained competitive advantage: A competency-based perspective," Acad. Manag. Rev., 19(4), 699-727, 1994.

[4] P. M. Wright, B. B. Dunford, and S. A. Snell, "Human resources and the resource based view of the firm," J. Manage., 27(6), 701721,2001

[5] J. A. Breaugh and M. Starke, "Research on employee recruitment So many studies, so many remaining questions," J. Manage., 26(3), 405-434, 2000.

[6] D. S. Chapman, K. L. Uggerslev, S. A. Carroll, K. A. Piasentin, and D. A. Jones, "Applicant attraction to organizations and job choice: A meta-analytic review of the correlates of recruiting outcomes," J. Appl. Psychol., 90(5), 928-944, 2005.

[7] K. L. Uggerslev, "Recruiting Through the stages: A meta-analytic test of predictors of applicant attraction at different stages of the recruiting process," Pers. Psychol., 65, 597-660, 2012.

[8] J. R. Crawshaw, R. Cropanzano, C. M. Bell, and T. Nadisic, "Organizational justice: New insights from behavioural ethics," Hum. Relations, 66(7), 885-904, 2013

[9] J. Greenberg, "Cultivating an image of justice: Looking fair on the job," Acad. Manag. Exec., 2(2), 155-158, 1988.

[10] M. Deutsch, "Equity, equality, and need: What determines which value will be used as the basis of distributive justice?," J. Soc. Issues, 31(3), 137-149, 1975.

[11] E. A. Lind and T. R. Tyler, The social psychology of procedural justice. Springer, 1988

[12] S. W. Gilliland, "The perceived fairness of selection systems: An organizational justice perspective," Acad. Manag. Rev., 18(4), 694-734, 1993.

[13] D. P. Skarlicki and C. T. Kulik, "Third-party reactions to employee (mis) treatment: A justice perspective," Research in Organizational Behavior, 26, 183-229, 2004

[14] D. E. Lewis, "Online water coolerlapplicants check message boards for word on a workplace," Boston Globe, 2000.

[15] R. Trigaux, "Bank-bashing goes digital at Internet gripe sites," Am. Banker, 164(58), 1999

[16] S. Clifford, "Video prank at domino's Taints brand," New York Times, 2009.

[17] S. Baker and H. Green, "Beyond blogs," Bus. Week, 2, 44-50, 2008
[18] D. Fost, "On the Internet, everyone can hear you complain," New York Times, 2008.

[19] M. Lynn, "Learning to live with the devil," Melb. Her. Sun, 2009.

[20] D. Schawbel, "Manage your online reputation-Before someone else does," Wall Str. Journal., 2010.

[21] C. T. Kulik, M. B. Pepper, D. L. Shapiro, and C. Cregan, "The electronic water cooler: Insiders and outsiders talk about organizational justice on the internet," Communic. Res., 39(5), 565-591, 2012.

[22] P. Zoghbi-Manrique-de-Lara, T. Aguiar-Quintana, and M. A. Suárez-Acosta, "A justice framework for understanding how guests react to hotel employee (mis)treatment," Tour. Manag., 36, 143$152,2013$.

[23] C. Porath, D. MacInnis, and V. Folkes, "Witnessing incivility among employees: Effects on consumer anger and negative inferences about companies," J. Consum., 37(2), 292-303, 2010.

[24] S. L. Blader, B. M. Wiesenfeld, M. Fortin, and S. L. WheelerSmith, "Fairness lies in the heart of the beholder: How the social emotions of third parties influence reactions to injustice," Organ. Behav. Hum. Decis. Process., 121(1), 62-80, 2013.

[25] B. Beersma and G. A. Van Kleef, "Why people gossip: An empirical analysis of social motives, antecedents, and consequences,” J. Appl. Soc. Psychol., 42(11), 2640-2670, 2012.

[26] J. Greenberg, "Organizational justice: Yesterday, today, and tomorrow," J. Manage., 16(2), 399-432, 1990.

[27] J. Greenberg, "The social side of fairness: Interpersonal and informational classes of organizational justice," in R. Cropanzano (Ed.), Justice in the Workplace. New Jersey: Lawrence Erlbaum Associates, 1993, pp. 79-103.

[28] Y. Cohen-Charash and P. E. Spector, "The role of justice in organizations: A meta-analysis," Organ. Behav. Hum. Decis. Process., 86(2), 278-321, 2001.

[29] J. A. Colquitt, "On the dimensionality of organizational justice: A construct validation of a measure," J. Appl. Psychol., 86(3), 386400, 2001.

[30] J. A. Colquitt, D. E. Conlon, M. J. Wesson, C. O. L. H. Porter, and K. Y. Ng, "Justice at the millennium: A meta-analytic review of 25 years of organizational justice research," Journal of Applied Psychology, 86(3). 425-445, 2001.

[31] R. Cropanzano, D. E. Bowen, and S. W. Gilliland, "The management of organizational justice," Acad. Manag. Perspect., 21, $34-48,2007$

[32] D. S. Chapman and J. Webster, "Toward an integrated model of applicant reactions and job choice," Int. J. Hum. Resour. Manag., 17(6), 1032-1057, 2006.

[33] C. M. Harold, B. C. Holtz, B. K. Griepentrog, L. M. Brewer, and S. M. Marsh, "Investigating the effects of applicant justice perceptions on job offer acceptance," Pers. Psychol., 69(1), 199-227, 2016.

[34] H. Zhao, "Turning small business interns into applicants: The mediating role of perceived justice," J. Bus. Ventur., 28(3), 443457, 2013.

[35] M. Baum, M. Schäfer, and R. Kabst, "Modeling the impact of advertisement-image congruity on applicant attraction," Hum. Resour. Manage., 55(1), 7-24, 2016.

[36] F. Lievens, G. Van Hoye, and F. Anseel, "Organizational identity and employer image: Towards a unifying framework," Br. J. Manag., 18, S45-59, 2007.

[37] R. Ployhart and A. Ryan, "Toward an explanation of applicant reactions: An examination of organizational justice and attribution frameworks,” Organ. Behav. Hum. Decis. Process., 72(3), 308-335, 1997.

[38] D. B. Turban, "Organizational attractiveness as an employer on college campuses: An examination of the applicant population," J. Vocat. Behav., 58(2), 293-312, 2001.

[39] L. Zhang and M. A. Gowan, "Corporate Social Responsibility, Applicants' Individual Traits, and Organizational Attraction: A Person-Organization Fit Perspective," J. Bus. Psychol., 27(3), 345$362,2012$.

[40] C. A. Pierce, K. A. Karl, and E. T. Brey, "Role of workplace romance policies and procedures on job pursuit intentions," $\mathrm{J}$ Manag. Psychol., 27(3), 237-263, 2012.

[41] R. J. Thompson, S. C. Payne, and A. B. Taylor, "Applicant attraction to flexible work arrangements: Separating the influence of flextime and flexplace," J. Occup. Organ. Psychol., 88(4), 726$749,2015$.

[42] D. B. Turban and D. W. Greening, "Corporate social performance and organizational attractiveness to prospective employees," Acad. Manag. J., 40(3), 658-672, 1997.

[43] W. C. Kim and R. Mauborgne, "Blue ocean strategy: From theory to practice," Calif. Manage. Rev., 47(3), 105-121, 2005. 
[44] L. Aiman-smith, T. N. Bauer, and D. M. Cable, "Are you attracted? Do you intend to pursue? A recruiting policy-capturing study," J. Bus. Psychol., 16(2), 219-237, 2001.

[45] J. Greenberg and E. A. Lind, "The pursuit of organizational justice: From conceptualization to implication to application," in E. Cooper and C. L.Locke (Eds.), I/O Psychology: What We Know About Theory and Practice. Oxford: Blackwell, 2000, pp. 72-105.

[46] B. S. Bell, D. Wiechmann, and A. M. Ryan, "Consequences of organizational justice expectations in a selection system," J. Appl. Psychol., 91(2), 455-66, 2006.

[47] M. C. Kernan and P. J. Hanges, "Survivor reactions to reorganization: Antecedents and consequences of procedural, interpersonal, and informational justice,” J. Appl. Psychol., 87(5), 916-928, 2002.

[48] D. B. Turban and D. M. Cable, "Firm reputation and applicant pol characteristics," J. Organ. Behav., 24(6), 733-751, 2003.

[49] C. Maden, "Antecedents and consequences of employees' justice perceptions in M\&As: A conceptual model," Proceedings of the Association of Management/International Association of Management, pp. 50-57, 2008.

[50] D. G. Allen, J. I. Hancock, J. M. Vardaman, and D. N. Mckee, "Analytical mindsets in turnover research," J. Organ. Behav., 35(S1), S61-86, 2014.

[51] W. J. Casper, C. Bordeaux, L. T. Eby, A. Lockwood, and D. Lambert, "A review of research methods in IO/OB work-family research,” J. Appl. Psychol., 92(1), 28-43, 2007.

[52] K. D. Miller and E. W. K. Tsang, "Testing management theories: Critical realist philosophy and research methods," Strateg. Manag. J., 32, 139-158, 2010.

[53] N. P. Podsakoff, P. M. Podsakoff, S. B. Mackenzie, T. D. Maynes, and T. M. Spoelma, "Consequences of unit-level organizational citizenship behaviors: A review and recommendations for future research," J. Organ. Behav., 35(S1), S87-119, 2014.

[54] D. A. Shepherd, "Multilevel entrepreneurship researh: Opportunities for studying entrepreneurial decision making," Journal of Management, 37(2), 412-420, 2011.

[55] M. a. Uy, M.-D. Foo, and H. Aguinis, "Using experience sampling methodology to advance entrepreneurship theory and research," Organ. Res. Methods, 13(1), 31-54, 2010.

[56] H. Aguinis and J. R. Edwards, "Methodological wishes for the next decade and how to make wishes come true," J. Manag. Stud., 51(1), 143-174, 2014.

[57] P. M. Podsakoff and D. R. Dalton, "Research methodology in organizational studies,” J. Manage., 13(2), 419-441, 1987.

[58] H. German, M. Fortin, and D. Read, "Justice judgments: Individual self-insight and between- and within-person consistency," Acad. Manag. Discov., 2(1), 33-50, 2016.

[59] A. M. Grant and T. D. Wall, "The neglected science and art of quasi-experimentation: Why-to, when-to, and how-to advice for organizational researchers," Organ. Res. Methods, 12(4), 653-686, 2009.

[60] H. Aguinis and K. J. Bradley, "Best practice recommendations for designing and implementing experimental vignette methodology studies," Organ. Res. Methods, 17(4), 351-371, 2014.

[61] R. Kumar, Research methodology: A step-by-step guide for beginners. Sage Publications, 2010.

[62] L. Aiman-Smith, S. E. Scullen, and S. H. Barr, "Conducting studies of decision making in organizational contexts: A tutorial for policycapturing and other regression-based techniques," Organ. Res. Methods, 5(4), 388-414, 2002.

[63] P. Cattin and D. R. Wittink, "Commercial use of conjoint analysis: A survey," J. Mark., 1982.

[64] P. E. Green and V. Srinivasan, "Conjoint analysis in marketing: new developments with implications for research and practice," $\mathrm{J}$ Mark., 46(3), 44-53, 1990.

[65] J. M. Mackay, S. H. Barr, and M. G. Kletke, "An empirical investigation of the effects of decision aids on problem-solving processes," Decis. Sci., 23(3), 648-672, 1992.

[66] W. Adamowicz, J. Louviere, and M. Williams, "Combining revealed and stated preference methods for valuing environmental amenities,” J. Environ. Econ. Manage., 26(3), 271-292, 1994.

[67] J. Mackenzie, "A comparison of contingent preference models," Am. J. Agric. Econ., 75(3), 593-603, 1993.

[68] S. H. Barr And M. A. Hitt, "A comparison of selection decision models in manager versus student samples," Pers. Psychol., 39(3), 599-617, 1986.

[69] S. L. Rynes and J. Lawler, "A policy-capturing investigation of the role of expectancies in decisions to pursue job alternatives," J. Appl. Psychol., 68(4), 620-631, 1983.

[70] A. J. Tomassetti, R. S. Dalal, and S. A. Kaplan, "Is policy capturing really more resistant than traditional self-report techniques to socially desirable responding?," Organ. Res. Methods, 19(2), 255285, 2016.

[71] R. J. Karren and M. W. Barringer, "A review and analysis of the policy-capturing methodology in organizational research Guidelines for research and practice," Organ. Res. Methods, 5(4), 337-361, 2002.

[72] S. L. Rynes And J. W. Boudreau, "College recruiting in large organizations: Practice, evaluation, and research implications," Pers. Psychol., 39(4), 729-757, 1986.

[73] W. Randy Evans and W. D. Davis, "An examination of perceived corporate citizenship, job applicant attraction, and CSR work role definition,” Bus. Soc., 50(3), 456-480, 2011.

[74] C. J. Collins and J. Han, "Exploring applicant pool quantity and quality: The effects of early recruitment practice strategies, corporate advertising, and firm reputation," Pers. Psychol., 57(3), 685-717, 2004.

[75] D. B. Turban, M. L. Forret, and C. L. Hendrickson, “Applicant attraction to firms: Influences of organization reputation, job and organizational attributes, and recruiter behaviors," J. Vocat. Behav., 44(52), 24-44, 1998.

[76] W. L. Gardner, B. J. Reithel, and R. T. Foley, "Attraction to organizational individualism - collectivism “ T," Manag. Commun. Q., 22(3), 437-472, 2009.

[77] L. Li and M. E. Roloff, "Organizational culture and compensation systems: An examination of job applicants' attraction to organizations,” Int. J. Organ. Anal., 15(3), 210-230, 2007.

[78] D. C. Feldman and H. J. Arnold, "Position choice: Comparing the importance of organizational and job factors," J. Appl. Psychol., 63(6), 706-710, 1978. 